\section{Conventional Selection versus Methods that Use Genotype $\times$ Environment Interaction in Sweet Corn Trials}

\author{
V.R. Bachireddy ${ }^{1}$, R. Payne, $\mathrm{Jr}^{2}$, and K.L. Chin ${ }^{1}$ \\ Department of Plant and Soil Sciences, College of Agriculture and Home \\ Economics, Southern University and A\&M College, Baton Rouge, \\ LA 70813
}

\author{
M.S. Kang ${ }^{1}$ \\ Department of Agronomy, Louisiana Agricultural Experiment Station, \\ Louisiana State University Agricultural Center, Baton Rouge, LA 70803
}

Additional index words. Zea mays, maize, stability variance statistics, heterogeneity, rank sum, environmental index, marketable ears

Abstract. The analysis of variance of a data set made up of 30 sweet corn (Zea mays L.) hybrids evaluated over 5 years for marketable ears (dozens per hectare) indicated a significant genotype (hybrid) $\times$ year $($ GY) interaction. Three selection methods were compared: 1) a conventional method based on mean yield alone (YA), 2) Kang's ranksum (KRS) method, and 3) Kang's modified rank-sum (KMR) method. The number of hybrids selected on the basis of YA, KRS, and KMR was 13. The KRS selected the lowest number of unstable hybrids (three) compared with the YA and KMR, which selected eight and six unstable hybrids, respectively. The mean yields of the selected hybrids were 3034 dozen/ha for YA, 2945 dozen/ha for KRS, and 3019 dozen/ha for KMR. The mean yield of KRS-selected hybrids and KMR-selected hybrids was $<2.9 \%$ and $0.5 \%$, respectively, than that of YA-based selections. This yield reduction was regarded as insignificant considering the farmer would be able to choose more consistently performing hybrids on the basis of KRS than on the basis of KMR or YA. Heterogeneity due to environmental index $\left(\overline{\mathbf{X}}_{\mathfrak{J}}-\overline{\mathbf{X}}_{. .}\right.$, where $\overline{\mathbf{X}}_{\mathfrak{J}}$ is the mean of all genotypes in the jth year and $X$ is the overall mean) was significant and was removed from the GY interaction. The removal of heterogeneity revealed that hybrids 77-2269, 116-Kandy Korn-EH, Golden Queen, 141-Sundance, Merit, and Stowell Evergreen were unstable because of a linear effect of the environmental index, and that hybrids 76-2681 and 806F-Truckers showed stable performance due to a linear effect of the environmental index.

Sweet corn hybrids grown in Louisiana are developed primarily by private seed companies in environments that are different from Louisiana's target environments.

Received for publication 13 May 1991. Accepted for publication 4 Feb. 1992. This work was supported by project LAX-82-2004-5053 of the U.S. Dept. of Agriculture, Coop. State Res. Serv., College of Agriculture and Home Economics, Southern Univ. and A\&M College, Baton Rouge, La. Publ. no. 105. The cost of publishing this paper was defrayed in part by the payment of page charges. Under postal regulations, this paper therefore must be hereby marked advertisement solely to indicate this fact.

'Professor.

${ }^{2}$ Research Assistant. oped in other states is evaluated in Louisian before recommending them for production to farmers. When a multiyear evaluation is made, hybrid performance may vary from year to year due to genotype $x$ environment interaction. Lack of consistency of genotype performance across locations or years provides additional information for the breeder (Busey, 1983). In addition to justifying the need for additional broad-based testing in different environments, the degree of inconsistency can help predict the variability expected among farms (Busey, 1983).

A large and significant genotype $\times$ environment $(\mathrm{GE})$ interaction hinders researchers' ability to recommend hybrids to farmers on the basis of mean performance (Kang et al., 1991). Integration of yield and stability of performance across years has generally not been practiced in performance trials, but is of utmost importance for selecting highyielding, stable genotypes (Kang and Pham, 1991). Kang and Pham (1991) evaluated methods for selecting genotypes on the basis of both yield and stability of performance. The methods included Hühn's (1979) $\quad \mathbf{S}_{\mathbf{i}}^{\mathbf{3}} ;$ and $\mathbf{S}_{i}^{\boldsymbol{\sigma}} \quad$ statistics, Lin and Binns' (1988) $\mathrm{P}_{\mathrm{i}}$ statistic, and Kang's (1988a) rank-sum statistic that uses Shukla's (1972) stability-variance statistic $\left(\hat{\sigma}_{i}^{2}\right)$. The $\hat{\sigma}_{i}^{2}$ is similar to Wricke's (1962) ecovalence $\left(\mathrm{W}_{\mathrm{i}}\right)$, which measures contribution of a genotype to GE interaction. Kang's (1988a) method, which assigns equal weight to yield and stability, was intermediate to Hühn's (1979) $S_{i}^{3}$ and $S_{i}^{6}$, and $P_{i}$ did not prove advantageous over either the ranksum method or Hühn's statistics. The ranksum method was considered a compromise between other methods (Kang and Pham, 1991).

Kang's rank-sum (KRS) method (Kang, 1988a) does not take into account significance level of $\hat{\sigma}_{\mathfrak{i}}^{2}$. Recently, Kang (1991) modified the KRS method; the new method [Kang's modified rank-sum (KMR) method] takes into consideration significance level of $\hat{\sigma}_{i}^{2}$. A significant $\hat{\sigma}_{i}^{2}$ indicates that performance of a genotype was unstable across environments.

Shukla (1972) extended his method to provide for use of a covariate to remove heterogeneity (nonadditivity) from GE interaction and partition the remainder of GE interaction variance into $\hat{s}_{i}^{2}$ components assignable to each genotype. A significant $\hat{\mathrm{s}}_{i}^{2}$ indicates that a genotype was unstable following removal of heterogeneity (the linear effect of a covariate) from GE interaction. A comparison of $\hat{\sigma}_{i}^{2}$ and $\hat{s}_{i}^{2}$ for a genotype reveals whether or not that genotype was stable or unstable due to the linear effect of the
Table 1. Analysis of variance for hybrid sweet corn yield (marketable ears, dozens per hectare) and partitioning of genotype $\times$ year interaction into heterogeneity and residual.

\begin{tabular}{lrc}
\hline \hline Source & df & Mean square \\
\hline Years (Y) & 4 & $39,120,958.9^{* *}$ \\
Replications within Y & 10 & $1,096,158.0^{* *}$ \\
Genotypes (G) & 29 & $1,150,112.0^{* *}$ \\
G $\times$ Y & 116 & $1,098,253.8^{* *}$ \\
Heterogeneity & 29 & $1,282,531.4^{* *}$ \\
$\quad$ Residual & 87 & $1,036,827.9^{* *}$ \\
Pooled error & 290 & $385,745.6$ \\
\hline
\end{tabular}

**Significant at $P=0.01$. 
Table 2. Yield (mean marketable ears, dozens per hectare), yield rank (X), stability-variance statistic ( $\left.\hat{\sigma}_{i}^{2}\right), \hat{\sigma}_{1}^{2}$ rank (Y), Kang's rank sum (KRS), stability rating (SR), Kang's modified rank sum (KMR), and $\hat{s}_{1}^{2}$ statistic ${ }^{2}$ for 30 sweet corn hybrids; and hybrids selected on the basis of yield alone, KRS $(X+Y)$, and KMR $(X+S R)$.

\begin{tabular}{|c|c|c|c|c|c|c|c|c|}
\hline Hybrid & $\begin{array}{c}\text { Yield } \\
\text { (dozen/ha) }\end{array}$ & $\begin{array}{l}\text { Yield rank } \\
(\mathrm{X})\end{array}$ & $\hat{\sigma}_{\mathbf{i}}^{2}$ & $\begin{array}{c}\hat{\sigma}_{\mathrm{i}}^{2} \\
\text { rank } \\
(\mathrm{Y})\end{array}$ & $\begin{array}{l}\text { Rank sum } \\
(X+Y)\end{array}$ & $\begin{array}{l}\text { Stability } \\
\text { rating } \\
\text { (SR) }\end{array}$ & $\begin{array}{c}X+S R \\
\text { sum }\end{array}$ & $s_{i}^{2}$ \\
\hline $77532-W X-9320$ & 3384 & $1(\mathrm{~S})^{\mathrm{y}}$ & $2791926^{* *}$ & 29 & $30(\mathrm{~S})$ & 8 & $9(S)$ & $3036446^{* *}$ \\
\hline Bellringer-102 & 3222 & $2(\mathrm{~S})$ & 757657 & 15 & $17(\mathrm{~S})$ & 0 & $2(S)$ & 783743 \\
\hline Miracle & 3171 & 3 (S) & $980808^{*}$ & 20 & $23(S)$ & 4 & 7 (S) & $1152685^{*}$ \\
\hline Sugar Loaf & 3060 & $4(S)$ & $8084418^{* *}$ & 30 & 34 & 8 & $12(\mathrm{~S})$ & $10772210^{* *}$ \\
\hline Silver Pac & 3024 & $5(\mathrm{~S})$ & $1752501^{* *}$ & 28 & 33 & 8 & $13(\mathrm{~S})$ & $915618^{*}$ \\
\hline 77530-WX-9001 & 2993 & $6(S)$ & 533197 & 9 & $15(S)$ & 0 & $6(S)$ & 223831 \\
\hline Seneca-258 & 2984 & 7 (S) & 300825 & 4 & $11(S)$ & 0 & 7 (S) & 411685 \\
\hline Calypso & 2971 & $8(S)$ & 343945 & 6 & $14(S)$ & 0 & $8(S)$ & 164666 \\
\hline $77-2269$ & 2958 & $9(\mathrm{~S})$ & $1226842^{*}$ & 23 & 32 & 4 & $13(S)$ & 89763 \\
\hline 116-Kandy Korn-EH & 2944 & $10(\mathrm{~S})$ & $1324424^{* *}$ & 24 & 34 & 8 & 18 & 141931 \\
\hline Mellogold & 2922 & $11(\mathrm{~S})$ & $957091^{*}$ & 19 & $30(\mathrm{~S})$ & 4 & $15(\mathrm{~S})$ & $1250023^{*}$ \\
\hline Golden Queen & 2912 & $12(S)$ & 1062199* & 21 & 33 & 4 & 16 & 793790 \\
\hline Debut & 2900 & $13(\mathrm{~S})$ & 144506 & 2 & $15(S)$ & 0 & $13(\mathrm{~S})$ & 98861 \\
\hline Northern Belle & 2842 & 14 & 762411 & 16 & 30 & 0 & $14(\mathrm{~S})$ & 909850 \\
\hline Guardian & 2810 & 15 & 640337 & 12 & $27(S)$ & 0 & $15(\mathrm{~S})$ & 863473 \\
\hline Paramount & 2813 & 16 & 747839 & 14 & 30 & 0 & 16 & 742629 \\
\hline 141-Sundance & 2766 & 17 & $1364932^{* *}$ & 26 & 43 & 8 & 25 & 335551 \\
\hline Florida Stay Sweet & 2763 & 18 & 319745 & 5 & $23(S)$ & 0 & 18 & 440632 \\
\hline Marada & 2761 & 19 & 399057 & 7 & $26(S)$ & 0 & 19 & 420802 \\
\hline NK-199 & 2750 & 20 & 574999 & 11 & 31 & 0 & 20 & 774769 \\
\hline 77533-BVX-5660 & 2716 & 21 & 149186 & 3 & $24(S)$ & 0 & 21 & 201913 \\
\hline $81-2267$ & 2681 & 22 & 95428 & 1 & $23(S)$ & 0 & 22 & 140950 \\
\hline $76-2681$ & 2646 & 23 & 917577 & 18 & 41 & 0 & 23 & $1137521^{*}$ \\
\hline 806F-Truckers & 2642 & 24 & 894290 & 17 & 41 & 0 & 24 & $1115570^{*}$ \\
\hline Silver Queen & 2621 & 25 & 703576 & 13 & 38 & 0 & 25 & 204248 \\
\hline Merit & 2520 & 26 & $1336302^{* *}$ & 25 & 51 & 8 & 34 & 613572 \\
\hline Bi-Queen & 2513 & 27 & 552408 & 10 & 37 & 0 & 27 & 227478 \\
\hline 1105-PVX-100 & 2434 & 28 & 482144 & 8 & 36 & 0 & 28 & 657736 \\
\hline Stowells Evergreen & 2156 & 29 & $1102358^{*}$ & 22 & 51 & 4 & 33 & 801388 \\
\hline 112-Sugar King & 2134 & 30 & $1645179^{* *}$ & 27 & 57 & 8 & 38 & $1681606^{* *}$ \\
\hline No. of hybrids selected & & 13 & & & 13 & & 13 & \\
\hline No. of unstable hybrids selected & & 8 & & & 3 & & 6 & \\
\hline Mean yield of selected hybrids & & 3034 & & & 2945 & & 3019 & \\
\hline Percent yield reduction & & 0 & & & 2.9 & & 0.5 & \\
\hline $\operatorname{LSD}(0.05)$ & 480 & & & & & & & \\
\hline $\mathrm{CV}(\%)$ & 22 & & & & & & & \\
\hline
\end{tabular}

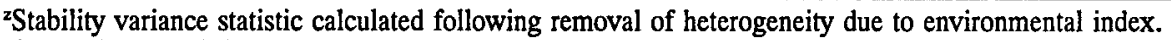
Y $S=$ selected hybrid.

*,**Significant at $P=0.05$ and 0.01 , respectively; also indicates that the hybrid performance across years was unstable.

covariate used. The covariate $\left(\mathrm{Z}_{\mathrm{j}}\right)$ can be any characteristic of the environment, e.g., temperature, rainfall, relative humidity, or environmental index.

The objectives of this investigation were: 1) to determine whether hybrid $\times$ year interaction existed in a data set made up of 30 sweet corn hybrids evaluated during 5 years (1984-88); 2) to compare selections based on a) yield alone (conventional method), b) KRS method, and c) KMR method; and 3) to determine whether stability or instability of a hybrid was due to the linear effect of the environmental index, $Z_{j},\left(Z_{j}=\bar{X}_{. j}-\right.$ $\overline{\mathrm{X}} .$. , where $\overline{\mathrm{X}}_{\mathrm{j}}$ is the mean of all genotypes in the jth year and $\mathbf{X}$ is the overall mean).

Performance of 30 sweet corn (commercial and experimental) hybrids was evaluated at Baton Rouge during 1984 to 1988 on an Olivier silt loam soil (Aquic Fragiudalf, finesilty, mixed, thermic). Each year, tests were planted in a triple rectangular lattice design. Single-row plots were $15.25 \mathrm{~m}$ long with 1.1 $\mathrm{m}$ between rows and $23 \mathrm{~cm}$ between plants (plant population of 39,536 plants/ha). Plots were fertilized with $67.3 \mathrm{~kg} \mathrm{~N}, \mathrm{P}$, and $\mathrm{K} / \mathrm{ha}$ of each, broadcast before planting, and sidedressed with $67.3 \mathrm{~N} \mathrm{~kg} / \mathrm{ha}$ when plants were $\approx 50 \mathrm{~cm}$ tall. Weed control was achieved with a preemergence application of Dual-8E herbicide, followed by two cultivations. 1-Napthy1 methyl carbamate (Sevin) insecticide was applied twice before emergence of silks and at 2-day intervals thereafter until harvesting began.

At maturity, yield (dozens per hectare of marketable ears, i.e., ears $12.5 \mathrm{~cm}$ or longer, after clipping the tip, with well-filled, undamaged kernels) for each plot was recorded and subjected to an analysis of variance (ANOVA). Because genotype $\times$ year $(\mathrm{GY})$ interaction was significant $(P<0.01)$, it was partitioned into heterogeneity and residual in accordance with Shukla (1972). The $\hat{\sigma}_{\mathbf{i}}^{2}$ and $\hat{\mathbf{s}}_{\mathrm{i}}^{2}$ statistics were computed using Kang's (1988b) BASIC program. For the KRS method, ranks were assigned for mean yield, with the hybrid having the highest yield receiving the rank of 1 . Similarly, ranks were assigned for $\hat{\sigma}_{\tilde{i}}^{2}$, with the lowest estimated value receiving the rank of 1 . A lower $\hat{\sigma}_{i}^{2}$ value implies a more stable hybrid. The two ranks for each hybrid were summed. A low rank-sum value was considered desirable.

For the KMR method, in addition to assigning yield ranks, a stability rating (SR) was assigned as follows: $\mathrm{SR}=0$ for nonsignificant $\hat{\sigma}_{i}^{2}$ at $P=0.05, \mathrm{SR}=4$ for $\hat{\sigma}_{i}^{2}$ significant at $P=0.05$ but nonsignificant at $P=0.01$, and $S R=8$ for $\hat{\sigma}_{i}^{2}$ significant at $P=0.01$. The SR value and yield rank for each hybrid were summed. A low sum was considered desirable.

Selections on the basis of yield rank alone were made by using the LSD $P=0.05$ value. All hybrids with yield within one LSD of the highest-yielding hybrid were selected. The same number of hybrids was selected using the KRS and KMR methods.

The ANOVA for yield of marketable ears (Table 1) indicated that the GY interaction was significant. Partitioning the GY interaction revealed that heterogeneity caused by the environmental index was significant, as was the residual. The significant GY interaction suggested that selection of hybrids on the basis of mean yield alone (YA) would not be appropriate. In such situations, methods that combine yield and stability of performance are useful.

Eight of the 13 hybrids selected on the basis of YA were unstable (Table 2). Mean yield of these 13 hybrids was 3034 dozen/ ha. When selection was based on the KRS 
method, eight hybrids were the same as those selected on the basis of YA. Only three of the 13 selected hybrids were unstable. The mean yield of the KRS-selected hybrids was $2945 \mathrm{dozen} / \mathrm{ha}$, which was $<2.9 \%$ the mean yield of hybrids selected on the basis of YA. Farmers may be willing to sacrifice $2.9 \%$ yield during 5 years when they are assured of a more consistent year-to-year performance.

When the KMR method was used, 11 of the selected hybrids were the same as those selected on the basis of YA (Table 2). Two additional hybrids (yield ranks 14 and 15), not selected by the YA method, were selected by the KMR method. The KMR selected six unstable hybrids, which is intermediate between the number of unstable hybrids selected by the YA method and that selected by the KRS method. Mean yield of the KMR-selected hybrids was 3019 dozen/ ha, which represents a $0.5 \%$ reduction in yield when compared with the YA-based selections. The farmer would be able to choose more consistently performing hybrids on the basis of KRS than KMR and YA. A farmer or researcher who is more oriented toward yield than stability may prefer to use the KMR method.

The use of an environmental index as a covariate removed heterogeneity from the GY interaction and provided additional information on the nature of stability of hybrids. When $\hat{\boldsymbol{\sigma}}_{\mathbf{i}}^{2}$ values were examined, 12 of 30 hybrids were labeled unstable (significant $\hat{\sigma}_{\mathbf{i}}^{\text {) }}$ (Table 2). After the linear effect of the environmental index was removed and $\hat{\mathbf{s}}_{\mathbf{i}}^{2}$ values were examined, eight instead of 12 hybrids were judged to be unstable (significant $\hat{\mathrm{s}}_{\mathrm{i}}^{\mathrm{i}}$. It was also revealed that hybrids 77 2269, 116-Kandy Korn-EH, Golden Queen, 141-Sundance, Merit, and Stowell Evergreen were unstable because of the linear effect of the environmental index. Conversely, two hybrids, 76-2681 and 806FTruckers, showed stable performance due to the linear effect of the environmental index, i.e., they were considered stable before removal of heterogeneity and were judged to be unstable after removal of heterogeneity due to the environmental index. Information such as this is important in understanding the nature and cause(s) of stability or instability of genotypes.

\section{Literature Cited}

Busey, P. 1983. Management of crop breeding, p. 31-54. In: D.R. Wood (ed.). Crop breeding. Amer. Soc. Agron., Crop Sci. Soc. Amer., Madison, Wis.

Hühn, M. 1979. Beiträge zur Erfassung der phänotypischen Stabilität. I. Vorschlag einiger auf Ranginformationen beruhenden Stabilitätsparameter. EDV Medizin und Biologie 10:112-117.

Kang, M.S. 1988a. A rank-sum method for selecting high yielding, stable corn genotypes. Cereal Res. Commun. 16:113-115.

Kang, M.S. 1988b. Interactive BASIC program for calculating stability-variance parameters. Agron. J. 80:153.

Kang, M.S. 1991. A modified rank-sum method for selecting high yielding, stable crop genotypes. Cereal Res. Commun. 19:361-364.
Kang, M.S., D.P. Gorman, and H.N. Pham. 1991. Application of a stability statistic to international maize yield trials. Theor. Applied Genet. 81:162-165.

Kang, M.S. and H.N. Pham. 1991. Simultaneous selection for high yielding and stable crop genotypes. Agron. J. 83:161-165.

Lin, C.S. and M.R. Binns. 1988. A superiority measure of cultivar performance for cultivar $x$ location data. Can. J. Plant Sci. 68:193-198.

Shukla, G.K. 1972. Some statistical aspects of partitioning genotype-environmental components of variability. Heredity 29:237-245.

Wricke, G. 1962. Uber eine Methode zur Erfassung der Ökologischen Streubreite in Feldversuchen. Z. Pflanzenzïchtg. 47:92-96. 